\title{
Partial Body UV Exposure in Chronic Kidney Disease and Extrarenal Vitamin D Metabolism
}

\author{
ROLFDIETER KRAUSE ${ }^{1,2,3}$, RAINER STANGE ${ }^{1,2}$, HEINZ JÜRGEN ROTH $^{4}$, \\ HEINRICH KAASE ${ }^{5}$, ANDREAS MICHALSEN ${ }^{1,2}$ and MICHAEL F. HOLICK ${ }^{6}$ \\ ${ }^{1}$ Research Group Medical Heliotherapy, University of Medicine Berlin, Berlin, Germany; \\ ${ }^{2}$ Department of Internal and Complementary Medicine, Immanuel Hospital, Berlin, Germany; \\ ${ }^{3} \mathrm{KfH}$-Curatorium for Dialysis and Kidney Transplantation, Neu-Isenburg, Germany; \\ ${ }^{4}$ Limbach Laboratory, Department of Endocrinology, Heidelberg, Germany; \\ ${ }^{5}$ Institute of Lighting Technics, Technical University, Berlin, Germany; \\ ${ }^{6}$ Section Endocrinology, Nutrition and Diabetes, Department of Medicine and Vitamin D, \\ Skin and Bone Research Laboratory, Boston University School of Medicine, Boston, MA, U.S.A.
}

\begin{abstract}
Background/Aim: Exposure of the skin to sunshine is the major natural source of vitamin D. In order to imitate this natural production of vitamin $D$ for patients with chronic kidney disease, hemodialysis patients were exposed three times a week to radiation of the front part of both legs to normalize the vitamin D status. Patients and Methods: Partial body UVB irradiation was performed during the routine dialysis session. Twenty-two patients took part, with a mean age of 61.7 (range $=35-81$ ) years. Results: Serum levels of $25(\mathrm{OH}) D_{3}$ and $1,25(\mathrm{OH})_{2} \mathrm{D}_{3}$ increased into the mid normal range. Intact parathyroid hormone decreased by $25 \%$ and osteocalcin by 45\%. 24-Hour blood-pressure monitoring demonstrated decreases in systolic and diastolic blood pressure. Conclusion: Partial body exposure to UVB radiation normalized not only the serum level of $25(\mathrm{OH}) D_{3}$, but also that of $1,25(\mathrm{OH})_{2} \mathrm{D}_{3}$, which resulted in a significant decrease in parathyroid hormone, osteocalcin levels, and also in blood pressure. Sunshine imitating UVB exposure utilizes the capacity of the skin to convert extrarenally vitamin $\mathrm{D}_{3}$ to $25(\mathrm{OH}) \mathrm{D}_{3}$ and $1,25(\mathrm{OH})_{2} \mathrm{D}_{3}$.
\end{abstract}

Exposure of the skin to sunshine is the natural process for producing vitamin D in humans. During exposure to sunlight,

Correspondence to: Rolfdieter Krause, MD, Research Group Medical Heliotherapy, Department of Internal and Complementary Medicine, Koenigstr. 63, D-14109 Berlin, Germany. Tel: +49 3080505691, Fax +49 3080505692, e-mail: rolfdieter.krause@gmx.de

Key Words: Vitamin D metabolism, partial body UVB irradiation, extrarenal synthesis, optimal blood levels of 25-hydroxyvitamin $\mathrm{D}_{3}$ (calcidiol) and 1,25-dihydroxyvitamin D3 (calcitriol), chronic kidney disease.
UVB radiation with wavelengths of $290-315 \mathrm{~nm}$ is absorbed by cutaneous 7-dehydrocholesterol (7-DHC) and is converted to previtamin $\mathrm{D}_{3}$. Once formed, thermally-labile pre-vitamin $\mathrm{D}_{3}$ isomerizes to vitamin $\mathrm{D}_{3}$ over several hours $(1,2)$. Once formed, vitamin $\mathrm{D}_{3}$ enters the circulation and is converted in the liver to 25-hydroxyvitamin $\mathrm{D}_{3}\left[25(\mathrm{OH}) \mathrm{D}_{3}\right]$. This major circulating metabolite is then converted in the kidneys to its active form 1,25-dihydroxyvitamin $\mathrm{D}_{3}\left[1,25(\mathrm{OH})_{2} \mathrm{D}_{3}\right](3,4)$.

In patients with chronic kidney disease (CKD) with progressive loss of kidney function, the ability to convert $25(\mathrm{OH}) \mathrm{D}_{3}$ to $1,25(\mathrm{OH})_{2} \mathrm{D}_{3}$ also decreases, resulting in decreased intestinal absorption of calcium resulting in secondary hyperparathyroidism. Although it is possible to increase the blood level of $25(\mathrm{OH}) \mathrm{D}_{3}$ in patients with CKD by giving vitamin $\mathrm{D}_{3}$, this does not result in an increase in the level of circulating $1,25(\mathrm{OH})_{2} \mathrm{D}_{3}(5)$.

In 1982 Lambert et al. demonstrated that patients with CKD were able to synthesize $1,25(\mathrm{OH})_{2} \mathrm{D}_{3}$ and the blood level of this hormone increased in patients who had undergone bilateral nephrectomy (6). Furthermore, it was reported that the production of vitamin $\mathrm{D}$ in the skin can result in its metabolism in the skin to $1,25(\mathrm{OH})_{2} \mathrm{D}_{3}(7)$.

In previous studies, our group demonstrated that wholebody suberythemal exposure to sun-simulated UVB radiation was able to normalize the serum levels of $25(\mathrm{OH}) \mathrm{D}_{3}$ and $1,25(\mathrm{OH})_{2} \mathrm{D}_{3}(8)$.

When the face, forearms and lower legs are exposed to the sun, this is equivalent to approximately $14-20 \%$ of the total surface of the body. Therefore in order to have a comparable area of exposure to activate the skin for extra-renal metabolism of vitamin D, the anterior part of both legs of the hemodialysis patients were exposed to solar-simulated UVB radiation, which corresponded to approximately $18 \%$ of their body surface. 


\section{Patients and Methods}

Twenty-two patients took part in this study, with a mean age of 61.7 (range $=35-81$ ) years, and mean time on dialysis of 3.6 (range $=0.5$ 6.0) years. UVB irradiation of the anterior legs was performed three times weekly over a period of 14 weeks during routine dialysis treatment. UVB-weighted irradiance [effective, UVB dose $\left(\mathrm{E}_{\mathrm{UVB}}\right)$ ] was to be $1.49 \mathrm{~W} / \mathrm{m}^{2}$, erythema-weighted irradiance (Eer) 0.21 $\mathrm{W} / \mathrm{m}^{2}$, vitamin D-weighted irradiance (EvitD) $0.33 \mathrm{~W} / \mathrm{m} 2$ for a distance of $0.24 \mathrm{~m}$ between the device and the patient; the duration of irradiance was calculated for skin type 2 of the irradiated parts of the legs. After 14 weeks, the mean vitamin D effective UV dose was 897.3 (range $=314.8-2,212.7) \mathrm{mJ} / \mathrm{cm}^{2}$.

Serum levels of $25(\mathrm{OH}) \mathrm{D}_{3}$ and $1,25(\mathrm{OH})_{2} \mathrm{D}_{3}$ were obtained at baseline before the start of the irradiance procedure and after 8 and 14 weeks of irradiation. In addition, the serum levels of intact parathyroid hormone (iPTH) and osteocalcin, a marker of bone turnover, were determined. at the same time (start, 8 and 14 weeks). Blood pressure monitoring on a 24 -h basis was performed before the start and at the end of the study period.

Statistics. The Medians and the ranges (lowest and highest of the individual data) are quoted. The Mann-Whitney $U$-test was used to test for differences in variables. A two-sided $p<0.05$ was considered significant.

\section{Results}

The vitamin D effective UVB dose after 8 weeks was 315.3 $\mathrm{mJ} / \mathrm{cm}^{2}$, and after 14 weeks it was increased nearly threefold to $897.3 \mathrm{~mJ} / \mathrm{cm}^{2}$. The serum level of $25(\mathrm{OH}) \mathrm{D}_{3}$ increased into the high normal range of between $70-78 \mathrm{ng} / \mathrm{ml}$ (median at week 8 and week 14 [range $=53-78 \mathrm{ng} / \mathrm{ml}]$. Serum levels of $1,25(\mathrm{OH})_{2} \mathrm{D}_{3}$ were also observed to increase into the normal range (median of $11 \mathrm{pg} / \mathrm{ml}$ after 4 weeks, and 19 $\mathrm{pg} / \mathrm{ml}$ after 14 weeks $[$ range $=9-19 \mathrm{pg} / \mathrm{ml}]$ ). There was also a nonlinear relationship between the vitamin $\mathrm{D}$ effective UVB dose $\left(\mathrm{E}_{\mathrm{UVB}}\right)$ and the serum level of $25(\mathrm{OH}) \mathrm{D}_{3}(\mathrm{r}=0.992)$, and a linear relationship between the serum levels of $25(\mathrm{OH}) \mathrm{D}_{3}$ and $1,25(\mathrm{OH})_{2} \mathrm{D}_{3}(\mathrm{r}=0.48)$.

The median iPTH level decreased by $25 \%$ from 12 to 9 (range $=3-44) \mathrm{pmol} / \mathrm{l}$. Osteocalcin decreased by $45 \%$ from 16 to 11 (range=7-25) $\mu \mathrm{g} / \mathrm{l}$ after 2 months and remained stable after 3 months during intermittent UVB irradiation. Serum calcium levels were stable (median $2.5 \mathrm{mmol}$ ) at start and after 4 weeks, and $2.4 \mathrm{mmol} / \mathrm{l}$ after 14 weeks (range=1.19$2.66 \mathrm{mmol} / \mathrm{l}$ ). Inorganic phosphate decreased from 1.83 $\mathrm{mmol} / \mathrm{l}$ at the start to $1.78 \mathrm{mmol} / \mathrm{l}$ after 4 weeks and to 1.68 $\mathrm{mmol} / \mathrm{l}$ after 14 weeks (range $=0.97-2.16 \mathrm{mmol} / \mathrm{l}$ ).

Blood-pressure monitoring before the start of the study period and at the end showed significant decreases of $6 \%$ and $7 \%$ in systolic blood pressure during daytime (141 to $133 \mathrm{mmHg}$, range $=102-176$ and $104-155 \mathrm{mmHg}$, respectively) and night time ( 145 to $135 \mathrm{mmHg}$, range $=104-$ 210 and 102-139 $\mathrm{mmHg}$, respectively). Diastolic blood pressure also decreased by $7 \%$ during daytime ( 81 to 75
$\mathrm{mmHg}$, range $=58-111$ and $51-81 \mathrm{mmHg}$, respectively) and $2 \%$ during the night time ( 71 to $70 \mathrm{mmHg}$, range $=47-86$ and 54-106 mmHg, respectively).

\section{Discussion}

Patients with CKD are unable to efficiently convert $25(\mathrm{OH}) \mathrm{D}_{3}$ to $1,25(\mathrm{OH})_{2} \mathrm{D}_{3}$ resulting in secondary hyperparathyroidism and renal osteodystrophy. Patients on hemodialysis are routinely treated with $1,25(\mathrm{OH})_{2} \mathrm{D}_{3}$ (calcitriol) or one of its active analogs. However, this treatment can result in hypercalcemia. Patients on hemodialysis are now routinely treated with $1,25(\mathrm{OH})_{2} \mathrm{D}_{3}$ or one of its analogs along with the calcimimetic, to help control the rise in the PTH level that is associated with CKD. Based on previous observations that had suggested that the skin not only is responsible for producing vitamin D during sun exposure but also has the enzymatic machinery to produce $1,25(\mathrm{OH})_{2} \mathrm{D}_{3}$, we initiated a study to evaluate the effect of whole-body irradiation with a sun-simulating UVB spectrum on the circulating levels of vitamin D and its metabolites. We observed remarkably that not only did this result in an increase in the serum levels of vitamin $\mathrm{D}$ and $25(\mathrm{OH}) \mathrm{D}_{3}$ but we also observed significant increases in that of $1,25(\mathrm{OH})_{2} \mathrm{D}_{3}(8)$. This treatment approach was more effective than after oral supplementation of a mean dose of $5,000 \mathrm{IU}$ of vitamin $\mathrm{D}_{3}$ per day (9).

We now report that partial body exposure to UVB irradiation has a similar effect to that of whole-body irradiation. After 2 months of regular UVB irradiation three times weekly of the front of the legs, $25(\mathrm{OH}) \mathrm{D}_{3}$ increased by $60 \%$ to $78 \mathrm{ng} / \mathrm{ml}$ and 1 month later, $1,25(\mathrm{OH})_{2} \mathrm{D}_{3}$ also increased by as much as $100 \%$ to $19 \mathrm{ng} / \mathrm{l}$. This provides confirmation of our previous studies $(8,9)$ and supports the observation of Lambert et al. (6). We found a strong relationship ( $\mathrm{r}=0.48)$ for serum levels of $25(\mathrm{OH}) \mathrm{D}_{3}$ over 25 $\mathrm{ng} / \mathrm{ml}$ to be associated with a significant increase in the level of circulating $1,25(\mathrm{OH})_{2} \mathrm{D}_{3}$.

In addition to normalization of the blood level of vitamin $\mathrm{D}$ metabolites, partial body irradiation, similarly to whole-body irradiation, was also associated with significant decreases in serum iPTH level. In addition there was a significant decrease in bone remodeling as demonstrated by a decrease in serum osteocalcin levels into the normal range (10).

We observed that partial body irradiation was effective in reducing blood pressure, similarly to what was observed with whole-body UVB irradiation (11). This observation is consistent with the data on geographical and seasonal variation of blood pressure i.e. lower latitudes and summer season was associated with decreased systolic and diastolic blood pressures $(12,13)$.

Therefore partial body exposure to UVB sun-simulated radiation may be an effective treatment for normalizing 
blood pressure in patients with end-stage kidney disease. Because cardiovascular comorbidities and cardiac death are highly prevalent in patients with chronic or end-stage kidney disease, this is of great importance for the quality of life and life expectancy of such patients (14-16).

In conclusion, as previously reported for sun-simulating whole-body irradiation, partial body (18\% surface area) exposure to UVB radiation similar to an amount of body surface that would be exposed to sunlight during the summer (face, forearms and lower legs) can normalize the vitamin D status into the mid to high normal range. This resulted in a significant increase in the circulating level of $1,25(\mathrm{OH})_{2} \mathrm{D}_{3}$, supporting the concept for the extra-renal production of $1,25(\mathrm{OH})_{2} \mathrm{D}_{3}$. The extra-renal production of $1,25(\mathrm{OH})_{2} \mathrm{D}_{3}$ in patients with CKD not only is important for their calcium and bone metabolism, but may also have important noncalcemic pleiotropic effects, including regulation of blood pressure and modulation of innate and adaptive immunity.

However, in order to take advantage of the extra-renal production of $1,25(\mathrm{OH})_{2} \mathrm{D}_{3}$ and to raise the blood $1,25(\mathrm{OH})_{2} \mathrm{D}_{3}$ level into the normal range in patients with $\mathrm{CKD}$, a $25(\mathrm{OH}) \mathrm{D}_{3}$ level in the range of $50-80 \mathrm{ng} / \mathrm{ml}$ may be required. Therefore, these data support the recommendation of the U.S. Endocrine Society (17) and of the Kidney Disease: Improving Global Outcomes Guidelines (18) that the normal range of $25(\mathrm{OH}) \mathrm{D}_{3}$ should be a minimum of 30 $\mathrm{ng} / \mathrm{ml}$ with a preferred range of $40-60 \mathrm{ng} / \mathrm{ml}$ for activating the extra-renal and autocrine conversion to $1,25(\mathrm{OH})_{2} \mathrm{D}_{3}$.

\section{References}

1 Chen TC, Lu Z and Holick MF: Photobiology of vitamin D. In: Vitamin D - Physiology, Molecular Biology, and Clinical Applications. MF Holick (ed.) Second Edition. New York Springer/Humana Press, pp. 35-60, 2010.

2 Holick MF: Photosynthesis of vitamin D in the skin: effect of enviromental and life-style variables. Fed Proc 146: 1876-1882, 1987

3 Jones G: Expanding role for vitamin D in chronic kidney disease: importance of blood 25-OH-D levels and extra-renal 1alpha-hydroxylase in the classical and nonclassical actions of 1alpha,25-dihydroxyvitamin D(3). Semin Dial 20: 316-324, 2007.

4 Holick MF: Vitamin D for health and in chronic kidney disease. Semin Dial 18: 266-275, 2005.
5 Gray RW, Weber HP, Dominquez JH and Lemann J Jr: The metabolism of vitamin $\mathrm{D}_{3}$ and 25 hydroxyvitamin $\mathrm{D}_{3}$ in normal and anephric humans. J Clin Endocrinol Metab 32: 1045-1056, 1974.

6 Lambert PW, Stern PH, Avioli RC, Brackett NC, Turner RT, Greene A and Fu IY: Evidence of extrarenal production of 1,25dihydroxivitamin D in man. J Clin Invest 69: 722-725, 1982.

7 Dusso A, Lopez-Hilker S, Rapp N and Slatopolsky E: Extrarenal production of calcitriol in chronic renal failure. Kidney Int 34(3): 368-375, 1988

8 Krause R: Vitamin D and UV exposure in chronic kidney disease. Dermato-Endocrinology 5: 109-116, 2013

9 Krause R, Roth HJ, Kaase H, Stange R and Holick MF: Vitamin D status in chronic kidney disease - UVB irradiation is superior to oral supplementation. Anticancer Res 36: 1397-1402, 2016.

10 Taal MW, Masud T, Green D and Cassidy MJ: Risk factors for reduced bone density in haemodialysis patients. Nephrol Dial Transplant 14: 1922-1928,1999.

11 Krause R, Bühring M, Hopfenmüller W, Holick MF and Sharma AM: Ultraviolet B and blood pressure. Lancet 52(9129): 709710, 1998.

12 Rostand SG: Ultraviolet light may contribute to geographical and racial blood pressure differences. Hypertension 30: 150-156, 1997.

13 Brennan PJ, Greenberg G, Miall WE and Tompson SG: Seasonal variation in arterial blood pressure. Br Med J 285: 919-923, 1982.

14 Krause R, Schober-Halstenberg HJ, Edenharter G, Haas K, Roth HJ and Frei U: Vitamin D status and mortality of German hemodialysis patients. AntiCancer Res 32: 391-396, 2012.

15 Brondum-Jacobsen P, Benn M, Jensen CB and Nordestgaard BC: 25-Hydroxyvitamin D levels and risk of ischemic heart disease, myocardila infarction, and early death. Arterioscler Thromb Vasc Biol 32: 2794-2802, 2012.

16 Mann CM, Hobbs AJ, Hemmelgarn BR, Roberts DJ, Ahmed SB and Rabi DM: Effect of oral vitamin D analogs on mortality and cardiovascular outcomes among adults with chronic kidney disease: a meta-analysis. Clin Kidney J 8: 41-48, 2015.

17 Holick MF, Binkley NC, Bischoff-Ferrari HA, Gordon CN, Hanley DA, Heeney RP, Murad MH and Weaver CM: Endocrine Society: Evaluation, treatment, and prevention of vitamin D deficiency: Endocrine Society clinical practice guideline. J Clin Endocrinol Metab 96: 1911-1930, 2011.

18 KDIGO Guideline for Chronic Kidney Disease - Mineral and Bone Disorder (CKD-MBD). Kidney Intern 76(Suppl 113): S1S130, 2017.

Received November 3, 2017

Revised December 4, 2017

Accepted December 8, 2017 